\title{
Periodontal approach of impacted and retained maxillary anterior teeth
}

\author{
N. Henner1, M. Pignoly*2, A. Antezack*3, V. Monnet-Corti*4 \\ 1 Former University Hospital Assistant Periodontology - Private Practice, 30000 Nîmes \\ 2 University Hospital Assistant Periodontology - Private Practice, 13012 Marseille \\ 3 Oral Medicine Resident, 13005 Marseille \\ 4. University Professor. Hospital practitioner. President of the French Society of Periodontology and \\ Oral Implantology \\ * Public Assistant for Marseille Hospitals (Timone-AP-HM Hospital, Odontology Department, \\ 264 rue Saint-Pierre, 13385 Marseille) \\ - Faculty of Odontology, Aix-Marseille University (27 boulevard Jean-Moulin, 13385 Marseille)
}

\begin{abstract}
Treatment of the impacted and retained teeth is a multidisciplinary approach involving close cooperation between periodontist and orthodontist.

Clinical and radiographic examination leading subsequently to diagnosis, remain the most important prerequisites permitting appropriate treatment.

Several surgical techniques are available to uncover impacted/retained tooth according to their position within the osseous and dental environment.

Moreover, to access to the tooth and to bond an orthodontic anchorage, the surgical techniques used during the surgical exposure must preserve the periodontium integrity. These surgical techniques are based on tissue manipulations derived from periodontal plastic surgery, permitting to establish and maintain long-term periodontal health.
\end{abstract}

\section{KEYWORDS}

Mucogingival surgery, periodontal plastic surgery, impacted tooth, retained tooth, surgical exposure

\section{INTRODUCTION}

A tooth is considered as impacted when it has not erupted after the physiological date and its follicular sac does not connect with the oral cavity. Impacted teeth can be located in a bone crypt, more or less at the level of the maxilla or mandible. Clinically, teeth are deemed as impacted in the absence of eruption 18 months after the usual date of eruption, when the root apices are edified and closed.

An impacted tooth must be differentiated from an enclosed tooth. The latter has not erupted but is connected with the oral cavity.

\section{Address for correspondence:}

Nicolas Henner - 4 Square de la Bouquerie - 30000 Nîmes

E-mail: cabinetdentaire.nimes@gmail.com

This is an Open Access article distributed under the terms of the Creative Commons Attribution License (http://creativecommons.org/licenses/by/4.0), which permits unrestricted use, distribution, and reproduction in any medium, provided the original work is properly cited. 
Impacted teeth can be left in place when there is still a chance they will erupt (immature tooth with unedified apices). Anatomical, physiological, or pathological obstacles prevent their eruption. If a retained tooth matures, it becomes an impacted teeth.

A tooth is considered dystopic or ectopic when it is in the wrong position, outside its eruption path.

The periodontal approach for impacted and retained teeth, also called surgical release, and involves the management of bone, connective, and epithelial tissues. It uses certain periodontal plastic surgery techniques that can be adapted to reach the impacted teeth and, at the same time, to adjust the marginal periodontium.

\section{IMPACTED AND RETAINED TEETH}

Impaction can be unilateral or bilateral. In the order of frequency, the most commonly impacted teeth are the third molars, then the maxillary canines, the maxillary central incisors, the second mandibular premolars, the mandibular canines, and the first molars $11,18,23,40$.

Impactions more frequently affect the female population (two-third of all impactions) than men, especially for the maxillary canines $6,30,34$.

According to some authors, palatal impaction of the maxillary canine is more frequent than vestibular inclusion (85\%) and $8 \%$ of these cases are bilateral. ${ }^{7}$. However, a more recent study using data obtained by cone-beam computerized tomography shows that $45.2 \%$
The objectives of surgical release are as follows:

- direct access to the clinical crown;

- osseomucosal release sufficient for bonding of orthodontic lock;

- tissue movement to recreate normal periodontal anatomy normal and/or compatible with preservation of periodontal health;

- emergence of the tooth in a dystopic site ${ }^{19}$.

Knowledge of the validity and presence of keratinized tissue around teeth during eruption, growth, puberty, and orthodontic treatment leads to many periodontal plastic surgery interventions being proposed in children and adolescents.

of the impacted maxillary canines are vestibular, $40.5 \%$ are palatal, and $14.3 \%$ are transalveolar ${ }^{39}$.

The prevalence of impacted canines is $1 \%-2 \%$ of the population ${ }^{11,13}$. Finally, $90 \%$ of the impactions are covered mainly with soft tissues ${ }^{24}$.

\section{Etiology}

Numerous etiological factors, whether general, regional, or local, may explain the impaction of certain teeth from the anterior sector of the maxilla. They are related to two etiological theories: genetic theory and guiding theory.

The etiology of inclusions is multifactorial. ${ }^{4}$ 


\section{Primary causes}

\section{- $\mathrm{Genetic}^{36}$}

There seems to be family predispositions to impaction. In fact, families were found in which the prevalence of an impacted maxillary canine was $4.9 \%$, which is 2.5 times greater than in the general population.

Major syndromes such as Gardner's syndrome, cleidocranial dysostosis, Down syndrome, Crouzon's syndrome, labioalveolopalatal clefts, and YunisVaron syndrome are usually associated with multiple inclusions.

- Endocrine deficiency

Certain disorders such as hypothyroidism and vitamin $A, C, D$ deficiencies cause growth disruption and may be the cause of dental retention and impaction ${ }^{26}$.

- Irradiation

- Labiopalatal cleft"3

Dental root development abnormality and isolated dysmorphia can affect the coronal or root part of the tooth, thus compromising its eruption. It can be congenital as a result of a temporary tooth trauma.

- Supernumerary teeth and odontoma (Fig. 1)
A supernumerary teeth are formed from an aberrant bud arising from a proliferation of the tooth or a bud splitting into two halves that evolve separately. The supernumerary tooth can be distinguished from normal (eumorphic) or abnormal (dysmorphic: conical, riceshaped) forms. Only $25 \%$ of them erupt in the oral cavity. In $80 \%$ cases, supernumerary teeth have a median position between the maxillary central incisors: they are then called "mesiodens."

Odontoma is a benign odontogenic tumor composed of tissues involved in odontogenesis. A compound odontoma is an amalgamation of small odontoid structures conforming to normal odontogenesis. Complex odontoma associates anarchically aggregated dental tissues. Its clinical manifestation is very discreet because it is painless to the touch and there is no cortical deformation. It is often only discovered by chance. Its location is maxillary in $60 \%$ cases, and more frequently in the anterior region ${ }^{37}$.

Whether for odontomas or supernumerary teeth, the absence of symptoms makes it impossible to suspect their presence. They are diagnosed through systematic and radiological screening. Rapid management often helps to remove these obstacles that immobilize permanent teeth or diverts them from their eruption path.

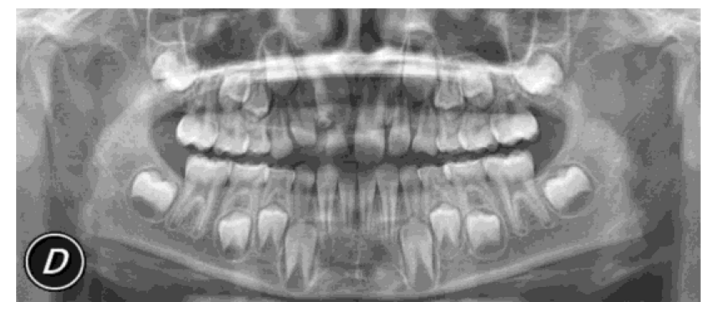

Figure 1

Presence of an odontoma leading to a delayed eruption of 11 and a delayed rhizalysis of 51. 
- Dentomaxillary disharmony (rather for vestibular inclusions)

A lack of space available on the arch can result from a primary etiology, either skeletal (brachygnathia) or dental (macrodontia). Because of the lack of available space, associated with or without dental congestion, the tooth remains impacted in a more or less distant position from the occlusion plane, inducing risks of root resorptions for adjacent teeth.

- Delay or absence of root formation of the tooth

- Differential growth between premaxillary and maxillary (for the maxillary canine)

- Maxillary brachygnathia

- Transverse deficiency of the anterior maxillary region ${ }^{33}$

\section{Secondary causes}

- Loss of guidance via agenesis of the lateral incisor ${ }^{14,36,38}$.

Proximal tooth agenesis sometimes induces a dental impaction via the loss of the role of eruption guide; this is called the "guidance theory," as opposition to the "genetic theory." 38 Indeed, during the eruption of maxillary canines, the contact is established, through the dental follicle, between the mesial side of the canines and the distal surface of the root of the lateral incisors. The intimate relationship between the canines and the root of the incisors suggests that the latter represents a guide that allows the canines to straighten up as they approach the occlusal plane and for the incisors to establish good proximal contacts.
It may be possible to establish a link between the frequency of impaction of maxillary canines-the second most frequently impacted tooth-and the agenesis frequency of the maxillary lateral incisors-the second most frequent cause of agenesis.

In case of agenesis of the lateral incisors, the impaction of the ipsilateral canine is usually palatal. Indeed, a palatal trajectory of the eruption of the maxillary canines coincides more with an excessive amount of developmental space or a lack of guidance of the lateral root rather than a lack of space $^{37}$.

- Trauma (maxillary deciduous incisors cause $15 \%$ cases of central maxillary incisor impactions)

- Decrease in the perimeter of the arch

Premature extraction of deciduous teeth causes the adjacent teeth to migrate and may block the path of the underlying germ, preventing its eruption and placement on the arch.

- Root malformation

- Pathology of the pericoronal sac

- Ectopic position of the germ

- Fibrous thickening ${ }^{17}$

The thickness of the scar tissue formed following the avulsion of deciduous teeth or gingival surgery may constitute a fibrous obstacle hindering the emergence of the permanent teeth.

This very thick fibromucosa is found in patients with a labioalveolopalatal cleft that has been operated on several occasions. This very dense scar tissue can be an obstacle to the physiological eruption of some teeth adjacent to the cleft. 
- The mesiodistal dimension of the nasal fossae and the architecture of the nasal fossae determines the location of the maxillary canine germs and conditions their eruption path in the transverse direction ${ }^{37}$. The intercanine distance is therefore a function of the width of the nasal fossae. In the presence of large nasal fossae, the intercanine distance is large and the convergence of the incisor roots is not very marked. Conversely, if the nasal fossae are narrow, the intercanine distance is then decreased and the convergence of the incisor roots is more marked ("ugly duckling" stage).

A relationship has therefore been established between the narrowness of the nasal fossae and a vestibular dystopia of the maxillary canine disturbing its eruption and may lead to impaction.

The width of the nasal fossae is related to the type of breathing. Therefore, children who are mouth breathers will have a lack of premaxillary and maxillary expansion that will cause dental congestion that may lead to canine impaction ${ }^{33}$.

\section{Diagnosis}

The patient never attends the dental office for consultation with an impacted tooth but complains about the consequences of the impaction. These include the impact on the aesthetics of their smile $(45.5 \%)$, functional problems $(39.4 \%)$, a combination of the two $(14.8 \%)$, or various complications (infectious, mechanical, etc.) related to the impaction in $0.3 \% 27$.

The clinical diagnosis is made through a medical questionnaire, a clinical intraoral examination, including a visual inspection and palpation (palatal or vestibular palatal cleft), and additional radiographic examinations.

\section{Clinical examination}

Practitioners should pay particular attention to the periodontal context they should be dealing with. Examining the quality of the periodontium allows them to anticipate the risks and the final result of a possible surgicalorthodontic treatment. Therefore, they verify at the level of the edentulous ridge the possibilities of lifting a flap, by evaluating the height of the keratinized tissue band.

The depth of the vestibule is measured to because it favors a good height of attached gingiva. The presence of a labial frenulum must also be taken into account. Indeed, if it is large, thick, or is attached near the alveolar ridge, it may hinder the healing that follows the extraction by creating too strong tissue tension. A frenectomy can then be considered, together with the release.

Finally, the location of the emergence point ${ }^{37}$ plays a key role in the periodontal prognosis of the impacted tooth pulled on the arch, and directs the orthodontist to optimize the periodontal environment. In fact, the position of the emergence point will depend on supporting tissue thickness, bone morphology and thickness, and gingival contours. It is defined by its situation related to the mucogingival line. In the case of a high and vestibular impaction, the pulled tooth can emerge in the alveolar mucosa and be deprived of attached gingiva. Preorthodontic periodontal plastic surgery optimizes the periodontal environment. It can also be used a posteriori in case of discomfort, 
need for repair, and to return to good periodontal health.

Special attention must be given to the delicate and fragile periodontium known as "at risk."

\section{Preoperative radiographic examination}

The first step in periodontal surgery is to identify the location of the tooth.

Although some 2D X-ray images, or their combination, allows us to find its location in the anteroposterior direction, it is more and more common to perform imaging in sections, with cone-beam computerized tomography (Fig 2).

This 3D imaging technique can only be indicated provided that it provides essential information that is not obtained by conventional techniques.

The 3D image provides 1:1 scale reconstructions, without distortion or overlay, and provides reliable information about:

- The location and orientation of the retained germs, in three dimensions, or in the form of volume reconstruction ${ }^{10}$.

- The location of the obstacles to eruption and their relationship with the impacted tooth.

- The external and internal anatomy of the impacted tooth.

- The vestibular and palatal bone thicknesses.

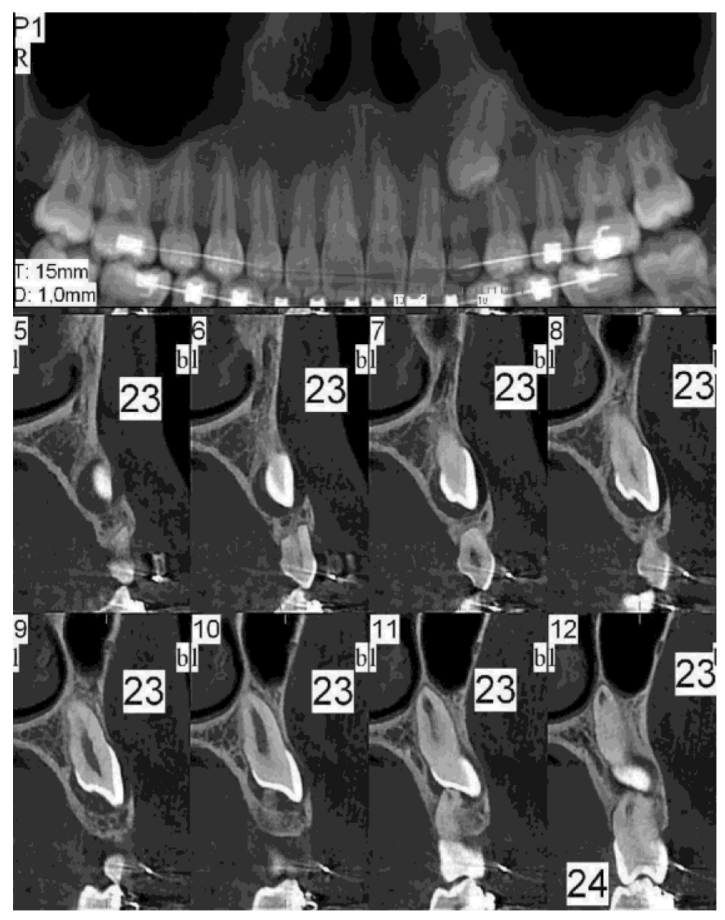

Figure 2

3D imaging (cone beam) that allows us to see a high and vestibular position of 23 and choose the appropriate approach. 
Possible resorptions of the teeth adjacent to the impacted tooth. 3D techniques can accurately diagnose root resorptions of teeth adjacent to the impacted tooth. Therefore, in the case of a maxillary canine impaction, one can note up to $27.2 \%$ root resorption in the lateral incisors and $23.4 \%$ in the central incisors ${ }^{39}$.

- The root resorptions of the impacted tooth itself, which may lead to the indication of avulsion rather than surgical release.

- The situation of the maxillary central incisor with respect to the nasopalatine canal and the nasal fossae, and of the mandibular canine relative to the inferior alveolar nerve.

- The presence or absence of radiolucent line spacing continues between the root of the impacted tooth and the bone, indicating ankylosis ${ }^{19}$.

\section{SURGICAL TECHNIQUES 35}

Maxillary canines will serve as a model for the description of each surgical approach. These techniques can be applied to other teeth, with some variations related to the anatomical situation of each.

First, sufficient space should be created or maintained on the arch before undergoing any orthodontic treatment. The receiving site must be arranged with an excess of space of $2 \mathrm{~mm}$ because the tooth often rotates in space, which increases the space required for its movements ${ }^{26}$. The layout of the space also makes it possible to validate the feasibility of the treatment
By obtaining precise anatomical data, this examination makes it possible to choose the best approach for a minor surgical procedure, and therefore preserve the periodontal tissues.

The surgical practitioner has, through this examination, a precise idea of the orientation of the impacted tooth and may consider the positioning of the attached fastener according to this orientation and the traction forces to be applied.

3D imaging is more than ever indicated to precisely locate the impacted tooth and the intimate relationships that it may have with adjacent structures despite it having more radiation risk than conventional X-rays, and its cost is not negligible. By simulating the surgical procedure while anticipating the movement of the impacted tooth, it allows for a minimally invasive surgery.

and to avoid resorption phenomena by the early movements of an impacted tooth, whose eruptive corridor has not been fully established.

Extraction of the deciduous teeth or premolars should be considered (especially in adults) only when the tooth has begun to move and there is no evidence of ankylosis.

The preservation of the deciduous tooth is motivated by aesthetic demands on the part of the patient (adolescent and adult) and for biomechanical reasons (maintenance of the mesiodistal space and the vestibulopalatal width of the alveolar ridge). 
However, it may be necessary to extract the tooth, to leave enough space to allow it to realize its natural eruption and its orthodontic positioning, and to have a zone of keratinized tissue transposable by a apically positioned flap or laterally and apically positioned flap.

The different techniques for surgical release of an impacted tooth are:

- vestibular:

- gingivectomy;

- the repositioned vestibular flap;

- the apically positioned flap;

- the flap positioned laterally and apically;

- palatine:

- the palatal flap repositioned, fenestrated or not

The indication of each vestibular technique is based on four criteria ${ }^{36}$ :

Criterion 1: The vertical position of the impacted tooth relative to the mucogingival line. If the tooth is positioned very apical to this line, the repositioned flap is indicated. Indeed, the gingivectomy would induce a significant vestibular recession and the apically displaced flap would cause risks of reintrusion or recurrence after orthodontic treatment, as well as aesthetic sequelae related to the formation of aesthetically damaging scarring.

Criterion 2: The vestibular or transalveolar position of the crown of the impacted tooth. While a crown with a vestibular position may indicate the four surgical techniques, a crown with a transalveolar position should indicate the repositioned flap.
Criterion 3: The amount of keratinized tissue around the impacted tooth. If it is weak, the flap should be moved apically to retain the keratinized tissue at the neck of the impacted tooth, unlike what is done in gingivectomy.

Criterion 4: The mesiodistal position of the crown of the impacted tooth. It is the displaced lateral flap which is indicated in this case. Indeed, the gingivectomy would jeopardize the marginal periodontium of the adjacent teeth.

\section{Gingivectomy}

Gingivectomy is indicated if high vestibular keratinized tissue height is observed opposite the tooth to be released and a crown of the impacted tooth is found to be in in the coronal position relative to the mucogingival line. ${ }^{20}$

A simple excision of the vestibular gingiva can reveal half or one-third of the crown, provided that $\geq 3 \mathrm{~mm}$ of marginal gingiva is left in place at the neck of the tooth.

Performing a single buttonhole technique in the alveolar mucosa ${ }^{2,10}$ is a poorly indicated technique on the periodontal plane.

\section{Repositioned vestibular flap (Fig. 3)}

It is indicated for certain teeth impacted in particular positions ${ }^{16,21,32,46}$ : when the tooth is in a high, very apical position, with respect to the mucogingival line or very high compared to this line (close to the nasal spine). It is also indicated when the impacted tooth is positioned in the middle of the alveolus. It will be technically impossible in these cases to position the tissues apically. 

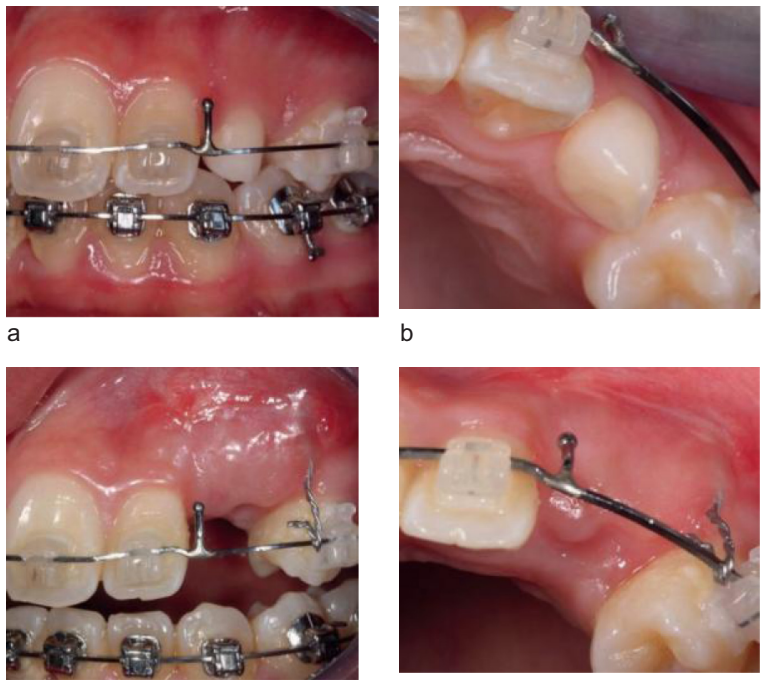

d

Figure 3

Vestibular flap repositioned because of the high position of 23 (see Figure 1).

(a) and (b) mesiodistal space built on the arch before extraction of 63 and surgical release

from 23 after 1 month. (c) and (d) Scarring of the flap at 2 months postoperatively.

\section{Apically positioned flap (Fig. 4)}

The apically positioned flap release is the first choice in many situations. It aims to create or maintain keratinized tissue around the tooth to be released, by apical displacement of the existing keratinized tissue through:

- the creation of a mucosal flap (or half-thickness flap or partial thickness flap);

- the preservation of the existing keratinized tissue by moving it to a more apical position and immobilizing it with a suture to the periosteum left in place;

- access to the tooth through a total thickness flap.

When bone still covers the crown, it is necessary to use a bone chisel, or a round bur mounted on a contra-angle handpiece working under physiological saline irrigation. Sometimes the tip of the stripper is sufficient to remove the bone shell and access the pericoronal sac. It is carefully trimmed to expose the crown, avoiding the total elimination of the tissue ${ }^{29}$.

\section{Apically and laterally positioned flap (Fig. 5)}

The indications for an apically and laterally positioned flap are the same as for an apically positioned flap except that the position of the tooth is lateral to the available keratinized tissue on the edentulous ridge or around an adjacent tooth. The route of the incisions of this flap therefore aims to clear the coronal part of the impacted tooth and by detaching/dissecting to transpose the 

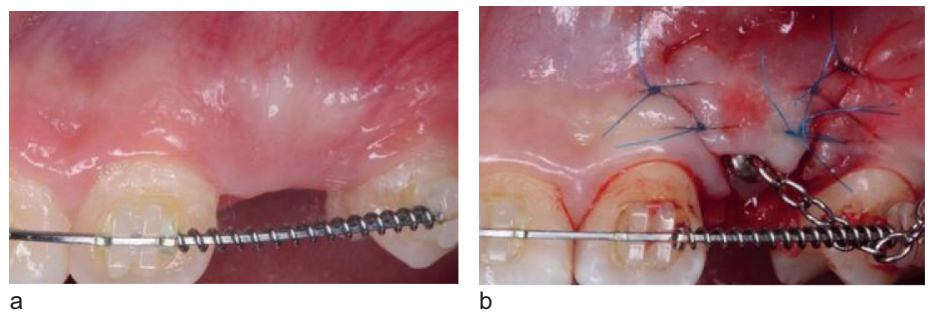

Figure 4

Release with a apically positioned flap. (a) Analysis of the environment of the impacted tooth: the thin periodontium, the small amount of keratinized tissue and the vertical position of the impacted tooth relative to the mucogingival line indicate the achievement of an apically positioned flap. (b) Part of the keratinized tissue of the edentulous ridge is positioned apically.

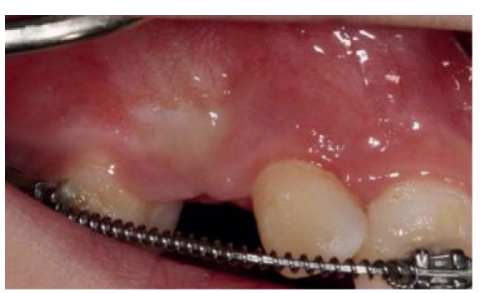

a

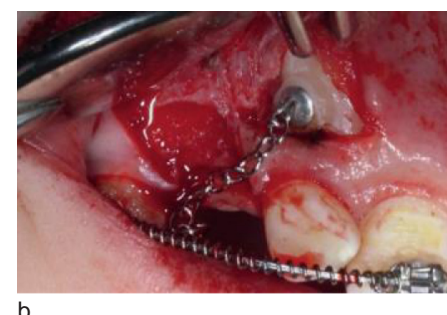

b

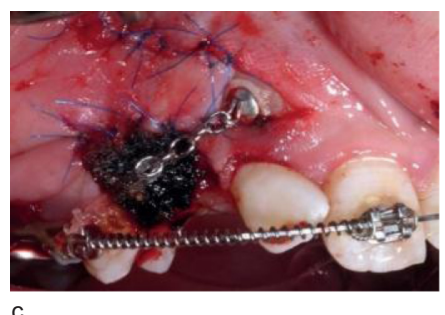

Figure 5

Release by apically and laterally positioned flap.

Preoperative situation: development of the mesiodistal space on the arch. (b) Exposing the crown and bonding the orthodontic attachment. (c) Monofilament sutures (6.0): part of the keratinized tissue of the edentulous ridge is positioned laterally and apically. The area of periosteal bone left bare is protected by Surgice ${ }^{\circledR}$.

keratinized tissue apically to the crown of the impacted tooth.

The area of exposed periosteal bone can be protected using a surgical dressing, it heals by second intention.

\section{Repositioned palatal flap (Fig. 6)}

This is the recommended technique in the presence of palatal impaction ${ }^{1,39}$

Direct access to the tooth by cutting a mucosal window directly is not recommended because the situation and dimensions of this window are very difficult to determine with precision,

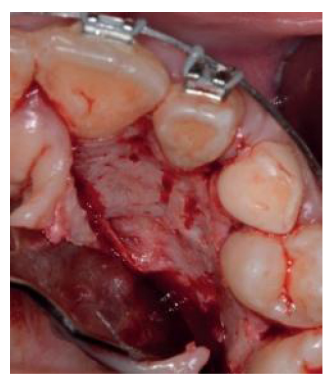

a

\section{Figure 6}

Release by repositioned palatal flap. (a) 23 is impacted in the palatal position, the deciduous canine is preserved. (b) The bone is removed using a bone chisel and part of the sac is excised. 
bone release is delicate and the bleeding is difficult to control for bonding.

The palatine impacted canine can be located in three different positions relative to the alveolus.

It may be:

- in a horizontal and apical position with respect to the central and lateral incisors;

- near the edentulous and mesial ridge to the lateral incisor;

- in a vertical position at the edentulous ridge.

No discharge incision is made. The detachment is full thickness. The tooth is visible because of the cortical curvature most of the time.

Crown release via osteotomy is more frequently associated with palatal osteotomy than vestibular osteotomy. During this bone release, care must be taken to respect the integrity of the roots of the adjacent teeth.

The flap is replaced, and a window is fitted through the flap.

The mucosal window should be larger than necessary because the connective budding of its edges tends to close the wound quickly and a 3-mm band of marginal gingiva must be ensured at the palatal neck of the teeth near the window. The arrangement of a mucosal window has many advantages. Indeed, even if the bonding is immediate, the attachment is not always ideally positioned but rather in a quasi-random situation that depends on the "presentation" of the clinical crown. It is common for the orthodontist to need to move the position of the fastener, or even to attach a second fastener to apply the forces best suited to the required movements. It also allows the practitioner to postpone the bonding of the clip, after removal of the surgical dressing, the area being dry and easily accessible ${ }^{36}$. In this window, the eruption appears to be accelerated and there is no evidence of loss of attachment, ankylosis, or resorption is ever observed ${ }^{8}$.

Important: the decision of whether the flap should be fenestrated depends on the position of the canine:

- a shallow tooth is released by a repositioned flap with window and intraoperative or delayed attachment of the fastener (made by the orthodontist);

- a deep tooth is released using a repositioned flap without a window and intraoperative bonding of the attachment.

Caution: the use of the electric scalpel is contraindicated.

The flap is sutured in its original position using sutures suspended in the palatal papillae.

The traction wire connected to the attachment exits the incision line (in the case of a nonwindowed flap) or the window (in the case of a windowed flap) and is passively attached to the orthodontic device while waiting to be activated by the orthodontist.

\section{Attachment bonding}

The fasteners indicated in this treatment are mainly orthodontic buttons and locks.

The surface of the released crown must be polished. This action eliminates organic debris adhering to the tooth, which generally impedes the 
bonding of the attachment. For optimal bonding, the release must also allow access to a coronal surface of $\geq 6 \mathrm{~mm}^{2}$ and preferably $9 \mathrm{~mm}^{2}$ where possible ${ }^{22}$. Obtaining a hemostasis allows bonding in good conditions remains the main challenge of the intervention. Although simple compression may be sufficient, stopping bleeding is sometimes more difficult to achieve, especially in the case of deep impactions.

If bleeding is from the flap, suction is ineffective, and it will be useful to use collagen powder ${ }^{41}$ or a Surgicel $\mathbb{R}$ compress. If bleeding comes from the pericoronal sac, compression will be sufficient.
The successful procedure on impacted teeth is based on good access to the clinical crown by respecting the cementoenamel junction, the presence of healthy and good-quality support tissues and, finally, on a good positioning on the arch.

Important: the results are predictable if certain fundamental principles are respected:

- a precise dissection without perforation;

- sufficient and limited bone and connective tissue release;

- in vestibular cases, an immobilization of the flap attached to the periosteum, itself adhered to the bone and tooth neck;

- in palatine cases, a wider release to avoid reoperation and performed with immense precision to not damage the surrounding structures.

\section{Clearing of the clinical crown}

All the techniques described above allow good access to the clinical crown and the possible bonding of an orthodontic attachment at least during the procedure.

\section{Quality of the periodontium around the tooth (Fig. 7)}

Some studies have investigated the effects of maxillary canine alignment on periodontal status and showed the presence of gingival recessions for vestibular inclusions. ${ }^{45}$ and a loss of attachment for palatal inclusions $\mathbf{s}^{5,25}$.

Clinical experience shows that the marginal periodontal tissue recreated by plastic surgery techniques resists probing and is stable over time.

According to Korbendau and Guyomard ${ }^{28}$, the attached gingiva follows the tooth in its movements. It is located at the same level as the neighboring teeth, has no change in height, and retains comparable thickness and quality.

Caminiti et al. ${ }^{9}$ out of 82 canines, there was never any infection, eruption failure, ankylosis, resorption, or periodontal injury. Only two teeth ( $9 \%$ cases) in the vestibular area showed $<3 \mathrm{~mm}$ of attached gingiva. 


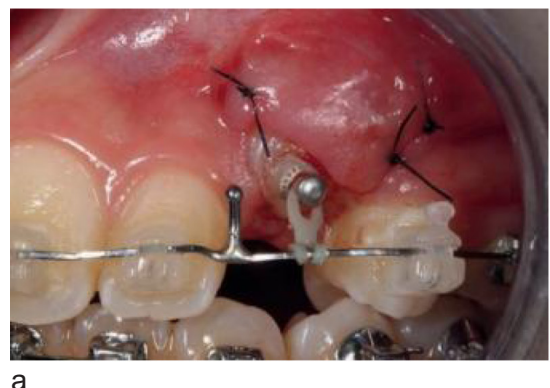

a

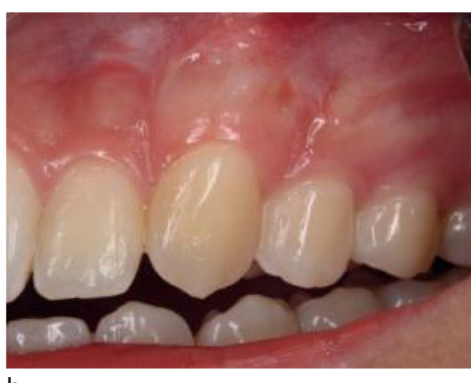

b

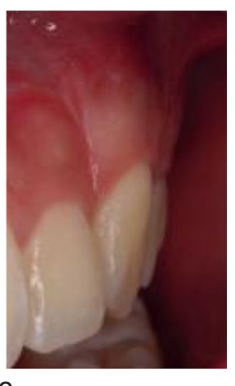

C

Figure 7

Quality and stability of the periodontium around the cleared tooth.

(a) Performance of a apically positioned flap. (b) and (c) Vestibular view and lateral view after 3 years.

\section{Setting up the tooth on the arch}

In some cases, the tooth is immobile. This may be because of insufficient bone release, inadequate orthodontic traction, or ankylosis.

Fleury et al. ${ }^{15}$ found $28 \%$ of ankylosed teeth out of 224 maxillary impacted canines. However, $77 \%$ of these teeth were treated after the age of 21 years.

Caminiti et al. $^{9}$ studied 82 maxillary canines cleared by vestibular or palatal flaps in 54 patients. Between 18 and 30 months after surgery, all the teeth were positioned on the arch.

The goal of the orthodontist is to achieve eruption without distortion of the occlusal plane or marginal tissue recession.

\section{Treatment complications}

Benign complications are represented by failures of intraoperative bonding, detachment after dressing removal, and during orthodontic traction.

Reoperation, gingival recessions, and bone loss are considered more severe complications ${ }^{42}$.
The problem of gingival recession is more relevant to the canines impacted in the vestibular position and the central incisors. Indeed, the surgicalorthodontic treatment of canines impacted in the palatal position rarely leads to these types of complications.

To avoid this kind of aesthetic inconvenience to the patient, the orthodontic traction forces must be gentle and progressive. A dental eruption is usually done with forces between 20 and $30 \mathrm{~g}$. However, an impacted tooth requires, for its placement on the arch, associated movements of rotation, egression, version, translation, and torque. The magnitude of the forces must not exceed $150 \mathrm{~g}$.

Other such severe complications can also be observed such as coronal resorption or internal resorption ${ }^{3.12}$, root resorptions of adjacent teeth (especially the central and lateral incisors), 13, 38 and ankylosis (in only $2 \%$ cases) $^{3}$.

When a surgical-orthodontic treatment is applied, the impacted tooth must be moved away from adjacent teeth to avoid resorptions of their roots. The distal movements of the canine 
impacted in the palatal position are therefore essential for the prevention of such phenomena involving the prognosis of adjacent teeth on the $\operatorname{arch}^{22}$.

It may also happen that, despite rigorous surgical-orthodontic treatment, no movement of the impacted tooth is observed after activation of orthodontic traction.

This immobility can be explained in different ways:

- insufficient osteotomy;

- orthodontic force directions not appropriate because of the angulation of the impacted tooth;

- detachment of the orthodontic attachment preventing effective traction of the impacted tooth20;

\section{CONCLUSION}

To optimize the medium-term and long-term results of the different periodontal approaches of the maxillary anterior teeth, both impacted and retained, the practitioner must respect certain principles. ${ }^{11}$ :

- prevention: an early diagnosis can immediately be managed, particularly by interceptive therapies (preventive guidance, conductive alveolectomy, directional osteotomy) and therefore increase the chances of a successful treatment;

- the establishment of a difficulty index: It helps the practitioner to choose the right treatment to apply, according to specific indications and their own skills;

- the establishment of a comprehensive therapeutic protocol in which the
- ankylosis of the impacted tooth. Although it can be diagnosed during preoperative examinations, it can sometimes be induced by the release surgery, which jeopardizes the future success of the orthodontic traction treatment of the tooth.

Although some authors propose a slight dislocation of the impacted tooth during its release to support or refute a hypothetical ankylosis, others recommend avoiding this technique which could itself be the cause of the ankylosis ${ }^{31}$.

practitioner and the orthodontist work in a multidisciplinary context.

If the impacted or retained tooth is not surgically cleared, there may be:

- root resorption of the adjacent tooth $\left(12 \%\right.$ cases $\left.^{14}\right)$;

- cystic formation or infection;

- periodontal injury;

- recurring pain 44 .

The possibility of complications (gingival recession, bone loss, root resorption, etc.) argues in favor of rigorous and close periodontal monitoring of cases of deimpaction.

Conflict of interest: The authors declare no conflicts of interest. 


\section{REFERENCES}

1. Abrams H, Gossett $S$, Morgan W. A modified flap design in exposing the palatally impacted canine. J Dent Child 1988;55:285-287.

2. Archer WH. Oral surgery. 4th ed. Philadelphie: WB Saunders Co, 1966.

3. Azaz B, Shteyer A. Resorption of the crown in impacted maxillary cuspid. Int J Oral Surg 1978;7:167171.

4. Bassigny F. Les signes prémonitoires d'inclusion des canines supérieures. Une approche préventive. Rev Orthop Dentofac 1990;24:91-102.

5. Becker A. Etiology of maxillary canine impactions. Am J Orthodont 1984;86:437-438.

6. Becker A, Kohavi D, Zilberman Y. Periodontal status following the aligment of palatally impacted canine teeth. Am J Orthodont 1983;84:332-336.

7. Bishara SE. Impacted maxillary canines: a review. Am J Orthodont Dentofacial Orthop 1992;101:159171.

8. Boyd RL. Clinical assessment of injuries in orthodontic movement of impacted teeth. I. Methods of attachment. Am J Orthodont 1982;82:478-486.

9. Caminiti MF, Sandor GK, Giambattistini C, Tompson B. Outcomes of the surgical exposure, bonding and eruption of 82 impacted maxillary canines. J Can Dent Assoc 1998;64:572-579.

10. Clark D. The management of impacted canines: free physiologic eruption. J Am Dent Assoc 1971;82:836- 840.

11. Dachi SF, Howell FV. A survey of 3,874 routine fullmouth radiographs. Oral Surg Med Oral Pathol 1961;14:1165-1169.

12. Dorfman DL. Idiopathic internal resorption of impacted maxillary cuspid. Dent Radiogr Photogr 1981;54:36-37.

13. Ericson SE, Kurol J. Radiographic examination of ectopically erupting maxillary canines. Am J Orthodont Dentofac Orthop 1987;91:483-492.

14. Ericson SE, Kurol J. Resorption of maxillary lateral incisors caused by ectopic eruption of the canines. A clinical and radiographic analysis of predispositing factors. Am J Orthodont Dentofac Orthop 1988:94:503-513.

15. Fleury JE, Deboets D, Assad-Auclair C, Maffre N, Sultan P. La canine incluse : mise au point à propos de 212 observations. Principes généraux de traitement. Rev Stomatol Chir Maxillofac 1985;86:122-131.

16. Fournier A, Turcotte J, Bernard C. Orthodontic considerations in the treatment of maxillary impacted canines. Am J Orthodont 1982;81:236-239.

17. Goho C. Delayed eruption due to overlying fibrous connective tissue: case reports. J Dent Child 1987;54:359-360.

18. Grover $P_{1}$ Lorton $L$. The incidence of unerupted permanent teeth and related clinical cases. Oral Surg 1985;59:420-424.

19. Guyomard F. Conditions de la réussite des interventions de chirurgie mucogingivale au cours du traitement orthodontique. Orthodont Fr 1998;69:131-140.

20. Hansson C, Rindler A. Periodontal conditions following surgical and orthodontic treatment of palatally impacted maxillary canines - A follow-up study. Angle Orthod 1998;68:167-172.

21. Hunter S. Treatment of the unerupted maxillary canine. Br Dent J 1983;154:294-296. 
22. Jacobs SG. The impacted maxillary canine. Further observations on aetiology, radiographic localization, prevention/interception of impaction, and when to suspect impaction. Aust Dent J 1996;41:310-316.

23. Johnsen DC. Prevalence of delayed emergence of permanent teeth as a result of local factors. J Am Dent Assoc 1977;94:100-106.

24. Johnston W. Treatment of palatally impacted canine teeth. Am J Orthodont 1969;56:589-596.

25. Kohavi D, Becker A, Zilberman Y. Surgical exposure, orthodontic movement, and final tooth position as factors in periodontal breakdown of treated palatally impacted canines. Am J Orthodont 1984;85:72-77.

26. Kokich VG, Mathews DP. Surgical and orthodontic management of impacted teeth. Dent Clin North Am 1993;37:181-204.

27. Korbendau JM, Guyomard F. Apport de la chirurgie parodontale à la mise en place des canines en dystopie vestibulaire. Rev Orthop Dentofac 1980;14:459-477.

28. Korbendau JM, Guyomard F. Mise en place des incisives retenues : problèmes muco-gingivaux et remaniements tissulaires. J Parodontol 1983;2:7-29.

29. Korbendau JM, Guyomard F. Chirurgie parodontale orthodontique. Paris : CdP, 1998.

30. Kuftinec MM, ShapiraY. The impacted maxillary canine. Review of concept. J Dent Child 1995;62:317324.

31. Kuftinec MM, Shapira Y. The impacted maxillary canine. II. Clinical approaches and solutions. J Dent Child 1995;62:325-334.

32. Magnusson H. Saving impacted teeth. J Clin Orthodont 1990;24:246-249.

33. McConnel TL, Hoffman DL, Forbes DP, Janzen EK, Weintraub NH. Maxillary canine impaction in patients with transverse maxillary deficiency. J Dent Child 1996;63:190-195.

34. McKay C. The unerupted maxillary canine, an assessment of the role of surgery in 2,500 treated cases. Brit Dent J 1978;145:207-210.

35. Monnet-Corti V, Pignoly M, Borghetti A. Dégagement par chirurgie plastique parodontale des dents incluses. In Borghetti A et Monnet-Corti V. Chirurgie plastique parodontale. Paris : Éditions CDP, 2017:539-553.

36. Pirinen $S$, Arte $S$, Apajalahti $S$. Palatal displacement of canine is genetic and related to congenital absence of teeth. J Dent Res 1996;75:1742-1746.

37. Rimes RJ, Mitchell CN, Willmot DR. Maxillary incisor root resorption in relation to the ectopic canine: a review of 26 patients. Eur J Orthodont 1997;19:79-84.

38. Sasakura H, Xoshida T, Murxama S, Hamada K, Makajima T. Root resorption of upper permanent incisor caused by impacted canine. An analysis of 23 cases. Int J Oral Surg 1984;13:299-306.

39. Smukler H, Castellucci G, Goldman H. Surgical management of palatally impacted cuspids. Compend Contin Educ Dent 1987;8:10-17.

40. Thilander B, Myrberg N. The prevalence of malocclusion in Svedial School children. Scand J Dent Res 1973;81:12-20.

41. Thomine F, Korbendau JM, Martineau C. Mise en place chirurgico-orthodontique des dents retenues. Real Clin 1995;6:351-369.

42. Vanarsdall RL, Corn $H$. Soft tissue management of labially positioned unerupted teeth. Am J Orthod 1977;72:53-64.

43. Vichi M, Franchi L. Eruption anomalies of the maxillary permanent cuspids in children with cleft lip and or palate. J Clin Pediatr Dent 1996;20:149-153. 
44. Wise RJ. Periodontal diagnosis and management of the impacted maxillary cuspid. Int J Periodont Rest Dent 1981;1:56-73.

45. Wisth PJ, Noderval K, Boe OE. Periodontal status of orthodontically treated impacted maxillary canines. Angle Orthod 1976;46:69-76.

46. Wong-Lee TK, Wong FC. Maintaining an ideal tooth-gingiva relationship when exposing and aligning an impacted tooth. Br J Orthod 1985;12:189-192.

47. À lire: Recommandations des Bonnes Pratiques: mise en place des canines incluses. Société Française de Stomatologie, Fédération Française de l'Orthodontie. 